\title{
Posterior Direkt Restorasyonlarda Nerede Başarısızlık Yaşıyoruz?
}

\author{
Ezgi SONKAYA ${ }^{1}$, Sema YAZICI AKBIYIK [ $^{2}$, Elif Pınar BAKIR ${ }^{3}$, Şeyhmus BAKIR ${ }^{3}$
}

\section{Öz}

Amaç: Amalgam ve kompozit rezinler, posterior bölgede en çok tercih edilen restoratif materyallerdir. Son yıllarda adeziv ve kompozit materyallerdeki gelişmeler sayesinde, posterior bölge çürük tedavisinde sıklıkla kompozit rezin restorasyonlar kullanılmaktadır. Bu çalışmanın amacı farklı merkezlerde, farklı materyallerle (amalgam ve kompozit) yapılan direkt posterior restorasyonların klinik performansını, restorasyona ve hastaya ait faktörler ile kesitsel bir çalışmayla karşılaştırarak değerlendirmektir.

Gereç ve Yöntemler: Çalışmada Dicle Üniversitesi Diş Hekimliği Fakültesi Restoratif Diş Tedavisi Anabilim Dalı'na başvuran 77 hastada, 365 restorasyon iki tecrübeli araştırıcı tarafindan Modifiye Rgye kriterlerine göre değerlendirilmiştir. Kriterlerin başarısız olma durumuna etkisi olan restorasyona ve hastaya bağlı değişkenleri tespit edebilmek için Ki-kare testi uygulanmıştır.

Bulgular: Hastaya ve restorasyona bağlı faktörlerin yapılan restorasyonların klinik performanslarına etkisi incelendiğinde, sonuçlara göre restorasyonun tipi, restorasyon derinliği, yapıldığı merkez, hastanın sigara içme alışkanlığı, parafonksiyonel alışkanlıkları ve oral hijyen alışkanlıklarının farklılığı restorasyon performansını anlamlı düzeyde etkilemiştir $(\mathrm{p}<0,05)$. Amalgam dolgu materyali kullanılarak yapılan restorasyonların başarısızlık oranı \%69 ve kompozit dolgu maddesi kullanılarak yapılan restorasyonların başarısızlık oranı \%50,8 olarak bulunmuştur.

Sonuç: Direk posterior restorasyonların ağız içi sağ kalım süresi, uygulayan diş hekimi tecrübesi ve bilgi birikimi, uygulama aşamalarındaki titizlik, restoratif materyali tanıma ve vakaya uygun seçim kriterleri bilgisi ile hastaya bağlı çeşitli faktörlerden de etkilenmektedir. Restorasyonların başarısının doğrudan bu etkenlere bağlı olduğunu görülmektedir.

Anahtar Kelimeler: Amalgam; klinik başarı; kompozit; restorasyon.

\section{Where Do We Fail in Posterior Direct Restorations?}

\begin{abstract}
Aim: Amalgam and composite resins are the most preferred restorative materials in the posterior side. Thanks to the developments in adhesives and composite materials in recent years, composite resin restorations are frequently used in the treatment of posterior caries. The aim of this study is to evaluate the clinical performance of direct posterior restorations performed with different materials in different centers, comparing the restoration and patient factors with a cross-sectional study.

Material and Methods: In the study, 365 restorations in 77 patients who applied to Dicle University Faculty of Dentistry Department of Restorative Dentistry, were evaluated according to Modified Rgye criteria by two researchers. Chi-square test was used to determine the variables that affect the failure of the criteria and to record the factors belonging to the restoration and the patient.

Results: When the effects of factors related to the patient and the restoration on the clinical performance of the restorations were examined, the difference between the type of restoration, the depth of the restoration, the center where it was performed, the patient's smoking, parafunctional and oral hygiene habits significantly affected the restoration performance ( $\mathrm{p}<0.05)$. The failure rate of restorations made using amalgam was $69 \%$ and the failure rate of restorations made using composite was $50.8 \%$.

Conclusion: The intraoral survival of direct posterior restorations is influenced by the experience and knowledge of the
\end{abstract}

1 Çukurova Üniversitesi, Diş Hekimliği Fakültesi, Restoratif Diş Tedavisi Anabilim Dalı, Adana, Türkiye

2 Diyarbakır ADSM, Diyarbakır, Türkiye

3 Dicle Üniversitesi, Diş Hekimliği Fakültesi, Restoratif Diş Tedavisi Anabilim Dalı, Diyarbakır, Türkiye 
practicing dentist, the meticulousness of the application stages, the knowledge of the restorative material recognition and selection criteria appropriate to the case, and various factors depending on the patient,and it shows that the success of the restorations directly depends on these factors.

Keywords: Amalgam; clinical success; composite; restoration.

\section{GÍRIŞ}

Son yıllarda dünya çapında, diş çürüğü prevalansında azalma olduğu gözlense de, tedavi edilmeyen çürükler, dünya nüfusunun yaklaşık \% 35'ini hala etkilemeye devam etmektedir (1). Diş çürüğü tedavisinde, direkt ve indirekt restorasyonlar en çok uygulanan tedavi prosedürleridir. Direkt posterior restorasyonlar, tedaviyi tek seansta bitirme imkanı, daha ekonomik olmaları, dişte daha az preparasyon gerekli olması gibi sebeplerden dolayı indirekt restorasyonlara göre daha çok tercih edilmektedir (2). Günümüzde dişlerin restorasyonunda kullanılmak üzere birçok restoratif materyal geliştirilmiştir. Amalgam ve kompozit rezinler, posterior bölgede en çok tercih edilen restoratif materyallerdir. Amalgam restorasyonlar, yüksek çiğneme kuvvetlerine sahip posterior bölge restorasyonlarında uzun yıllardır başarılı bir şekilde kullanılmaktadır. Maliyeti düşüktür ve klinik uygulamada teknik hassasiyet gerektirmemektedir (3). Ancak estetik olmaması, dişe sadece mekanik olarak bağlanması ve adeziv sistemlerdeki son gelişmeler sayesinde, günümüzde kompozit rezinlere eğilim artmıştır. Kompozit rezinlerin tercih edilme sebepleri arasında, estetik olmaları, diş dokularına kimyasal ve mikromekanik olarak bağlanabilmeleri, translüsens özelliklerinin doğal dişe yakın olması, tamir edilebilir ve cilalanabilir olma özellikleri yer almaktadır (4).

Restoratif materyallerin klinik performansları ve ağız içindeki dayanım süreleri, kullanılan materyalin fiziksel özelliklerinin yanı sıra, ağız içinde uygulandığı diş bölgesi, restorasyonun büyüklüğü ve lokalizasyonu, hastanın çiğneme alışkanlıkları ve çiğneme kuvveti, hastanın ağız hijyeni ve çürüğe yatkınlığı gibi birçok faktörden etkilenmektedir (5). Ayrica hekime bağlı faktörlerin de restoratif materyallerin klinik performansı üzerine etkisi olduğu belirtilmiştir (6). Restorasyonların klinik başarısızlığında, kalan diş dokusuna göre restorasyonun yenilenmesi, dişe kanal tedavisi ya da çekim yapılması alternatiflerinden birisi uygulanmalıdır. Ancak tüm bu seçenekler klinikte hasta ve hekime zaman kaybı, tatminsizlik, özellikle hastaya ve ülke ekonomisine yüksek maliyet getirmektedir (7).

Posterior restorasyonların klinik performansın değerlendirilmesi ile ilgili birçok prospektif ve retrospektif çalışma bulunmaktadır (8). Günümüzde kullanılan ve her yeni gün geliştirilip piyasaya sunulan özellikle adeziv tekniklerde ve kompozit rezin materyallerinin içeriğindeki gelişmelerle, restorasyonların klinik performasını değerlendirmek için bu çalışmaların belirli zaman aralıklarında yenilenmesine ihtiyaç duyulmaktadır. Restorasyon için kullanılan materyalin türü, kavite derinliği ve lokalizasyonu, hastanın yaşı, cinsiyeti, diş firçalama alışkanlığı, diş hekimi ziyaretlerinin aralığ1, restorasyonun nerede uygulandığ 1 ve uygulayan hekimin tecrübesi gibi faktörlerin posterior restorasyonların klinik performansını etkilediği bildirilmiştir $(9,10)$.

$\mathrm{Bu}$ kesitsel çalışmanın amacı; ülkemizdeki çeşitli tedavi merkezlerinden hizmet almış olan ve sonrasında fakültemize müracaat eden hastaların posterior dişlerinde, mevcut olan diş restorasyonlarının klinik ve radyolojik olarak incelenmesiyle başarılı ve başarısız olup olmadığını saptamaktır. Restorasyona ve hastaya ait faktörlerin, restorasyonların klinik performansına etkilerini göstermektir.

$\mathrm{Bu}$ çalışmanın sıfır hipotezi; hastaya ve restorasyona ait özelliklerin direk restorasyonların klinik performansına etkisi olmayacağıdır.

\section{GEREÇ VE YÖNTEMLER}

Kesitsel çalışmamız Dicle Üniversitesi Diş Hekimliği Fakültesi Klinik Araştırmalar Etik Kurul onayı (2019/20) ile gerçekleştirildi. Çalışmamızdaki veriler Ağustos 2020Ocak 2021 tarihleri arasında Dicle Üniversitesi Diş Hekimliği Fakültesi Restoratif Diş Tedavisi kliniğine başvuran minimum bir tane posterior dolgusu olan 16-65 yaş grubundaki (\%32,9'u 16-25, \%56,4'ü 25-45 ve $\% 10,7$ 'si $45-65$ yaş aralığı), toplam 77 hastadan (46 kadın, 31 erkek hasta) toplanmıştır. Hastaların çoğunlukla farklı eğitim düzeylerinde olduğu, çok sayıda restorasyonu olduğu ve bu restorasyonların farklı merkezlerde yapıldığı görülmüştür ve hepsi değerlendirmeye katılmıştır. Çalışma için gerekli bilgilendirmeler yapılıp, onam formları alınmıştır. Toplamda 365 farklı restorasyon, klinik ve radyografik olarak değerlendirilmiştir. Değerlendirmeler iki gözlemci tarafından yapılmış ve gözlemciler arasındaki uyum Cohen Kappa testi baz alınarak aralarındaki uyum minimum 0,8 olana kadar farklı restorasyonlarda değerlendirilerek sağlanmıştır. Muayene sırasında dental tedavi geçmişini hatırlamayanlar, işlemler konusunda kesin bilgiler veremeyenler ve uyum zorluğu yaşayan hastalar dışarıda bırakılacak şekilde, Modifiye Ryge (United States Public Health Services) kriterleri kullanılarak restorasyon kayıtları tutulmuştur. Restorasyonlar reflektör 1şı̆̆ında, tükrük uzaklaştırılarak ayna-sond ile inspeksiyon muayenesinin yanı sira hastanın panoramik, periapikal ve bite-wing filmleri de değerlendirilerek muayene edilmişlerdir. Hastaya bağlı faktörler olan parafonksiyonel ve oral hijyen alışkanlıkları, diş hekimine gitme sıklığı, sigara kullanımı (Tablo 1) ile restorasyona bağlı faktörler olan restorasyon tipi, derinliği, yaşı, yapıldığı yer ile kavite tipi de kayıt altına alınmıştır (Tablo 2).

Modifiye Ryge kriterlerine göre restorasyonlar renk uyumu, kenar renklenmesi, kenar uyumu, anatomik form, yüzey pürüzlülüğü, retansiyon, sekonder çürük oluşumu ve postoperatif hassasiyet açısından değerlendirilmiştir. Gözlemciler skorlamaları sırasında birbiriyle koopere olarak çalışmış ve ortak kararlar almıştır. Retansiyon, renk uyumu, kenar renklenmesi, kenar uyumu, anatomik form ve yüzey pürüzlülüğü kriterleri A, B, C skorlarıyla A: başarılı, $\mathrm{B}$ : orta ve $\mathrm{C}$ : başarısız olacak şekilde skorlanıp, bu kriterlerden A ve B skorlarını alan restorasyonlar başarılı kabul edilirken, C skorunu alan dişler başarısız olarak kabul edilmiştir. 
Tablo 1. Hastaya bağlı değerlendirilen faktörler

\begin{tabular}{|c|c|c|c|c|}
\hline Hastaya bağlı değerlendirilen & \multicolumn{4}{|c|}{ Kriterler } \\
\hline Yaş & $16-25$ & $25-45$ & $45-65$ & \\
\hline Cinsiyet & Kadın & Erkek & & \\
\hline Eğitim Düzeyi & İlkokul- Ortaokul & Lise & $\begin{array}{l}\text { Üniversite- } \\
\text { Yüksekokul }\end{array}$ & $\begin{array}{c}\text { Yüksek lisans, Master } \\
\text { Doktora }\end{array}$ \\
\hline Diş hekimine gitme sıklığ1 & Dişi ağrıdığ1 zaman & 2-3 yılda bir & 5-6 yılda bir & \\
\hline Sigara Kullanımı & Var & Yok & & \\
\hline Parafonksiyonel Alışkanlıklar & Geceleri diş sıkma & Sakız çiğneme & Bruksizm & \\
\hline Oral Hijyen Alışkanlıkları & $\begin{array}{l}\text { Her gün 1-2 kez } \\
\text { dişlerini firçalıyor }\end{array}$ & $\begin{array}{c}\text { Haftada 1-2 kez } \\
\text { dişlerini firçalıyor }\end{array}$ & $\begin{array}{c}\text { Ayda 1-2 kez } \\
\text { dişlerini firçalıyor }\end{array}$ & Dişlerini Fırçalamıyor \\
\hline
\end{tabular}

Tablo 2. Restorasyona bağlı değerlendirilen faktörler

\begin{tabular}{|c|c|c|c|c|}
\hline Restorasyona bağli & \multicolumn{4}{|c|}{ Kriterler } \\
\hline Restorasyonun Tipi & Amalgam & Kompozit & & \\
\hline Kavite Sinıflandırılması & Oklüzal & OM-OD & MOD & \\
\hline Restorasyonun Derinliği & Siğ & Orta & Derin & Çok Derin \\
\hline Restorasyonun Yaş1 & 2 yildan az süre & $3-5$ y1l & $6-10$ yil & 10 yıldan fazla süre \\
\hline Restorasyonun Yapıldığ Y Yer & $\begin{array}{c}\text { ADSM } \\
\text { sağlığ }(\text { merkeziz ve Diş }\end{array}$ & Serbest Hekim & Stajyer Hekim & $\begin{array}{c}\text { Üniversite Öğretim } \\
\text { Eleman1 }\end{array}$ \\
\hline
\end{tabular}

Tablo 3. Modifiye Ryge Kriterleri

\begin{tabular}{|c|c|c|c|}
\hline & \multicolumn{3}{|c|}{ Skorlama } \\
\hline Kriterler & $\mathrm{A}=\mathrm{Alfa}$ & $\mathrm{B}=$ Bravo & $\mathrm{C}=$ Charlie \\
\hline Retansiyon & $\begin{array}{l}\text { Restorasyon ağı içinde, } \\
\text { olması gerektiği şekilde }\end{array}$ & $\begin{array}{l}\text { Restorasyonun belki bir k1smı } \\
\text { düşmüş, bir k1smı yerinden hareket } \\
\text { etmiş ancak restorasyon yine de } \\
\text { ağızda }\end{array}$ & $\begin{array}{c}\text { Restorasyonun tamamiyle ağız } \\
\text { içinde değil }\end{array}$ \\
\hline Renk uyumu & $\begin{array}{l}\text { Restorasyonun hue, } \\
\text { chroma ve value değerleri } \\
\text { komşu diş ile uyumlu }\end{array}$ & $\begin{array}{l}\text { Restorasyonun hue, chroma ve } \\
\text { value değerleri komşu diş ile } \\
\text { uyumsuz ancak diş rengi sınırları } \\
\text { içinde }\end{array}$ & $\begin{array}{l}\text { Klinik olarak kabul edilemez } \\
\text { hue, chroma ve value değerleri }\end{array}$ \\
\hline Marjinal kenar renklenmesi & $\begin{array}{l}\text { Restorasyonla kalan diş } \\
\text { dokusu birleşim hizasında } \\
\text { renk değişikliği yok }\end{array}$ & $\begin{array}{l}\text { Restorasyonla kalan diş dokusu } \\
\text { birleşim hizasında lokal, } \\
\text { çoğunlukla temizlenebilir yüzeyel } \\
\text { renk değişikleri mevcut }\end{array}$ & $\begin{array}{c}\text { Restorasyonla kalan diş } \\
\text { dokusu birleşim hizasını aşmış } \\
\text { ve pulpa yönüne doğru } \\
\text { ilerlemiş renklenme }\end{array}$ \\
\hline Anatomik form & $\begin{array}{l}\text { Restorasyon diş sınırları } \\
\text { ile anatomik bir } \\
\text { devamlılık gösteriyor }\end{array}$ & $\begin{array}{l}\text { Restorasyon ile diş arasında klinik } \\
\text { olarak kabul edilebilir sınırlar } \\
\text { içerisinde genel bir aşınma mevcut }\end{array}$ & $\begin{array}{l}\text { Restorasyon ile diş arasında } \\
\text { mine-dentin sınırının altına } \\
\text { uzanan aşınma mevcudiyeti } \\
\text { var }\end{array}$ \\
\hline Marjinal Adaptasyon & $\begin{array}{c}\text { Restorasyonun tüm } \\
\text { sınırları çevresini saran diş } \\
\text { dokusun ile adapte, sond } \\
\text { takılmıyor }\end{array}$ & $\begin{array}{l}\text { Restorasyon ile diş arasına sond } \\
\text { takılıyor, ancak dentin henüz } \\
\text { açıkta değil }\end{array}$ & $\begin{array}{l}\text { Restorasyon ile diş arasına } \\
\text { sond takılıyor, dentin açıkta }\end{array}$ \\
\hline Yüzey Pürüzlülüğü & $\begin{array}{l}\text { Dolgunun yüzeyi ve onu } \\
\text { saran mine dokusu } \\
\text { pürüzlülüğü aynı } \\
\end{array}$ & $\begin{array}{l}\text { Dolgunun yüzeyi ve onu saran } \\
\text { mine dokusu pürüzlülüğ̈ farkl1, } \\
\text { restorasyon yüzeyi daha pürüzlü }\end{array}$ & $\begin{array}{c}\text { Restorasyon yüzeyinde çatlak } \\
\text { ve kırıklar meydana gelmiş, } \\
\text { yenilenme gerekir }\end{array}$ \\
\hline Sekonder çürük & Çürük yok & $\begin{array}{c}\text { Restorasyonla diş arasında } \\
\text { yumuşak lezyon, opasite veya } \\
\text { beyaz nokta gibi çürük belirtileri } \\
\text { var }\end{array}$ & \\
\hline Postoperatif hassasiyet & Hassasiyet yok & Hassasiyet var & \\
\hline Gingival Enflamasyon & Gingival enflamasyon yok & Gingival enflamasyon var & \\
\hline
\end{tabular}


Sekonder çürük oluşumu, postoperatif hassasiyet ve gingival enflamasyon kriterleri ise A ve B skorlariyla A: başarılı, B: başarısız olacak şekilde skorlanmışlardır (Tablo 3). Genel değerlendirmede ise herhangi bir kriterden başarısız olan restorasyon, başarısız olarak skorlanmıştır.

\section{İstatiksel Analiz}

Araştırmaya katılan hastaların cinsiyet, yaş, eğitim düzeyleri, diş hekimine ziyaret sıklıkları, sigara kullanımları ve oral hijyen alışkanlıklarının frekans dağılımları verilmiştir. Kavite sınıflandırmasına göre restorasyon tipleri çapraz tablo kullanılarak yorumlanmıştır. Kriterlerin başarısız olma durumlarına etkisi olan değişkenleri tespit edebilmek için Ki-kare testi uygulanmıştır. $\mathrm{p}<0,05$ anlamlılık düzeyi kabul edilmiştir.

\section{BULGULAR}

Kesitsel çalışmamızda, 129 amalgam (\%44,2'si oklüzal, \%47,3'ü OM-OD, \%8,5'u MOD) ve 236 kompozit (\%38,1'i oklüzal, \%50,4'ü OM-OD, \%11,4'ü MOD) olmak üzere toplamda 365 posterior direk restorasyon incelenmiştir (Tablo 4).

Tablo 4. Restorasyonların kavite sınıflandırmasına göre

\begin{tabular}{|l|l|c|c|c|c|}
\hline \multicolumn{2}{|c|}{} & \multicolumn{3}{|c|}{ Kavite Sınıflandırılması } & \\
\cline { 3 - 6 } \multicolumn{2}{|c|}{$\begin{array}{l}\text { Restorasyon } \\
\text { Tipi }\end{array}$} & Oklüzal & OM-OD & MOD & Toplam \\
\cline { 2 - 6 } & & $57(44,2)$ & $61(47,3)$ & $\begin{array}{c}11 \\
(8,5)\end{array}$ & 129 \\
\cline { 2 - 6 } & Kompozit & $90(38,1)$ & $\begin{array}{c}119 \\
(50,4)\end{array}$ & $\begin{array}{c}27 \\
(11,5)\end{array}$ & 236 \\
\cline { 2 - 6 } & & & & & 365 \\
\hline
\end{tabular}

değerlendirilmesi [n (\%)]

Araştırmaya katılan katılımcıların \%60'1 kadın, \%40’1 erkektir. Katılımcıların \%32'si 16-25 yaş gurubunda, $\% 56$ 's $25-45$ ve \%12'si 45-65 yaş gurubundadır. \%19'unun eğitim durumu ilkokul-ortaokul, \%34'ünün lise, \%35'inin üniversite-yüksekokul, \%12'sinin yüksek lisans-doktoradır. Katılımcıların \%90'ı dişi ağrıdığ zaman, \%10'u 2-3 yılda bir diş hekimine gitmektedir. Katılımcıların \%39'u sigara içerken, \%61'i sigara içmemektedir. Katılımcıların \%77'si her gün 1-2 kez dişlerini firçalama, \%19'u haftada 1-2 kez firçalama, $\% 1$ 'i ayda 1-2 kez firçalama ve \%2'si firçalamama alışkanlıklarına sahiptir. $\mathrm{Bu}$ veriler araştırmaya katılan bireylerin ortalama düzeyde eğitim ve dental bilgi seviyesine sahip olduğunu göstermektedir.

$\mathrm{Bu}$ değerlendirmelere göre başarısızlık sebebi olarak en çok restorasyonların renk uyumsuzluğu olduğu $(\% 32,3)$, bunu takip eden başarısızlık sebeplerinin sırasıyla restorasyonların anatomik formlarının $(\% 31,5)$, yüzey yapılarının $(\% 24,7)$ istenildiği gibi olmaması ve sekonder çürük $(\% 22,7)$ olduğu görülmüştür. Ayrıca 6-10 yıllık restorasyonların retansiyon $(p=0,001)$, marjinal kenar renklemesi $(p=0,001)$, renk uyumu $(p=0,037)$, yüzey yapısı $(p=0,044)$ ve sekonder çürük $(p=0,004)$ açısından anlamlı düzeyde farklılık gösterdiği görülmüştür (Tablo $5-6)$.
Tablo 5. Restorasyonların Rgye kriterlerine göre başarıbaşarısızlık bulguları $(\mathrm{n}=365)$ [n (\%)]

\begin{tabular}{|l|c|c|c|}
\hline \multirow{2}{*}{} & Başarılı & Başarısız \\
\cline { 2 - 4 } & $\mathrm{A}$ & $\mathrm{B}$ & $\mathrm{C}$ \\
\hline Retansiyon & $285(78,06)$ & $33(9,04)$ & $47(12,8)$ \\
\hline Renk Uyumu & $109(29,9)$ & $138(37,8)$ & $118(32,3)$ \\
\hline $\begin{array}{l}\text { Marjinal Kenar } \\
\text { Renklenmesi }\end{array}$ & $183(50,1)$ & $101(27,7)$ & $81(22,2)$ \\
\hline $\begin{array}{l}\text { Anatomik } \\
\text { Form }\end{array}$ & $99(27,1)$ & $151(41,4)$ & $115(31,5)$ \\
\hline $\begin{array}{l}\text { Marjinal } \\
\text { Adaptasyon }\end{array}$ & $178(51,2)$ & $103(28,2)$ & $75(20,5)$ \\
\hline Yüzey Yapı1s1 & $138(37,8)$ & $137(37,5)$ & $90(24,7)$ \\
\hline \multicolumn{3}{|l}{}
\end{tabular}

Tablo 6. Restorasyonların Rgye kriterlerine göre başarıbaşarısızlık bulguları $(n=365)$ [n (\%)]

\begin{tabular}{|c|c|c|}
\hline & Başarılı & Başarısız \\
\cline { 2 - 3 } & $\mathrm{A}$ & $\mathrm{B}$ \\
\hline Sekonder Çürük & $282(77,3)$ & $83(22,7)$ \\
\hline Retansiyon & $318(87,1)$ & $47(12,8)$ \\
\hline Postoperatif Hassasiyet & $300(82,2)$ & $65(17,8)$ \\
\hline Gingival İnflamasyon & $339(92,9)$ & $26(7,1)$ \\
\hline
\end{tabular}

Hastaya ve restorasyona bağlı faktörlerin, yapılan restorasyonların klinik performanslarına etkisi incelendiğinde, sonuçlara göre restorasyonun tipi, restorasyon derinliği, yapıldığı merkez, hastanın sigara içme alışkanlığı, parafonksiyonel alışkanlıkları ve oral hijyen alışkanlıkları farklılı̆̆ 1 restorasyon performansını anlamlı düzeyde etkilemiştir $(\mathrm{p}<0,05)$. Yapılan istatiksel analizler sonucu, amalgam dolgu maddesi kullanılarak yapılan restorasyonların başarısızlık oranı \%69 ve kompozit dolgu maddesi kullanılarak yapılan restorasyonların başarısızlık oranı $\% 50,8$ olarak bulunmuştur ve aralarında anlamlı bir fark bulunmaktadır $(p=0,001)$. Kompozit restorasyonların başarı oranı daha yüksektir. Sı̆̆ restorasyonlarda başarı oranı $\% 46,2$, orta restorasyonlarda başarı $\% 50,6$, derin restorasyonlarda başarı \%36,3 ve çok derin restorasyonlarda başarı $\% 25$ olarak tespit edilmiştir ve aralarında anlamlı bir fark bulunmaktadır $(\mathrm{p}=0,011)$. Restorasyonlardaki en yüksek başarı oranı üniversite öğretim elemanı tarafindan yapıldığında (\%27,6's1 başarısız, \%72,4'ü başarıl1), en yüksek başarısızlık oranı ise ağız ve diş sağlığ başarısız, \%28,3'ü başarılı) yapılan restorasyonların olduğu görülmektedir ( $\mathrm{p}=0,001)$.

Sigara içenlerde başarı oranı $\% 34,1$ ve sigara içmeyenlerde başarı oranı \%47,5 olarak tespit edilmiştir $(\mathrm{p}=0,014)$. Parafonksiyonel alışkanlığı olmayanların başarı oranı \%44,3, geceleri diş sıkma alışkanlığı olanların \%44,3, sakız çiğneme alışkanlığı olanların \%16 ve bruksizm olanların başarı oranı \%47,5 olarak tespit edilmiştir $(\mathrm{p}=0,046)$. Her gün 1-2 kez diş firçalayanlarda başarı oranı \%49,7 iken, haftada 1-2 kez dişlerini firçalayanlarda başarı \%22,2'ye düşmekte ve ayda 1-2 kez ila dişlerini hiç firçalamayan hasta grubunda başarı görülmemiştir ( $\mathrm{p}=0,001)$. 


\section{TARTIŞMA}

Kompozit materyallerinin, doğal dişin renk özelliklerini taklit edebilmesi, minimal invaziv yöntemlere izin vermesi, diş dokusuna adezyonunun giderek güçlenmesi, uygulama basamaklarının azaltılması gibi özellikler sayesinde son yıllarda klinik kullanımları artmıştır. Ancak Türkiye'de her bölgenin kendine özgü sosyoekonomik, kültürel şartları ve alışkanlıkları bulunmaktadır. Dolayısıyla günümüzde amalgam, dolgu materyali olarak halen kullanılmaktadır. Çalışmamızın da amac1, posterior direk restorasyonlarının hastaya ve restorasyona bağlı özellikleri göz önüne alınarak klinik performanslarını değerlendirmektir.

Yıllar içinde, birçok çalışma da posterior ve anterior kompozit restorasyonların klinik ömrü değerlendirmiştir. Sistematik derlemeler, kompozit restorasyonların \%1 ila \%4 arasında değişen yıllık başarısızlık oranları ile iyi klinik performansa sahip olabileceğini göstermiştir (1114). Bununla birlikte, restorasyonların başarısızlıkları sonucu yenilenmesi kamu hastaneleri ve özel kliniklerde hala çok sık karşılaşılan, azımsanamayacak miktarda zaman ve sağlık sistemleri için yüksek ek maliyetler yaratan bir durumdur. Bu maliyetleri belirleyebilmek için yapılan araştırmalar coğrafi farklılıklar, araştırmanın yapıldığı zaman gibi çeşitli faktörlerden etkilenmektedir. $\mathrm{Bu}$ sebeplerle farklı zaman periyotlarında, ülkenin farklı bölgelerinde yeniden tekrarlanması gereklidir. $\mathrm{Bu}$ durumun ne kadar ciddi boyutlara ulaştığıyla ilgili bilgi elde edinmek için farklı merkezlerde ve farklı hekimler tarafından uygulanmış restorasyonları, ancak istatiksel olarak karar verilen örneklem sayısıyla, kesitsel dizayn çalışmalarla gözlemlemek mümkündür. Çalışmamızı da bu durumu belirlemek için kesitsel bir yöntem kullanarak planladık. Ancak tüm dünyayı saran pandemi koşulları nedeniyle kliniklere başvuran hasta sayısı azlığından dolayı belirli sayıda hasta üzerinde çalışmamızı gerçekleştirebildik. Aynı zamanda hastalardan alınan bilgilerin doğruluğu yalnızca hastanın sözel bilgilendirmesi ile olması çalışmamızın sınırlamalarıdır. Çalışmamızın sonuçları dikkate alındığında sıfır hipotezimiz reddedilmiştir. Restorasyonun tipi, kavite derinliği, uygulandığı merkez ve uygulayan kişinin bilgi ve deneyimi gibi kriterlerin direk posterior restorasyonların başarısını etkilediği görülmüştür.

Amalgam restorasyonlarda en sik görülen başarısızlık nedeni olarak, uygulama sırasında kütlesel yerleştirilmesi sonucu, duvar adaptasyonunda bozukluklar yaratması nedeniyle sekonder çürük oluşumu bulunmuştur (15). Kompozit rezin restorasyonlarda ise sik görülen başarısızlık nedenleri arasında; uygulamadaki teknik zorluklar ve materyalin polimerizasyon büzülmesi gibi nedenlerden kaynaklı renk uyumsuzlukları, aşınma, kırık, marjinal kenar sızıntısı ve sekonder çürük oluşumu yer almaktadır $(14,16)$.

Çalışmamızda başarısızlık sebebi olarak en yüksek, restorasyonların renk uyumsuzluğu olduğu $(\% 32,3)$, bunu takip eden başarısızlık sebeplerinin sirasıyla, restorasyonların anatomik formlarının $(\% 31,5)$, yüzey yapılarının $(\% 24,7)$ kabul edilebilir düzeyde olmaması ve sekonder çürük $(\% 22,7)$ olduğu görülmüştür. Ayrıca 6-10 y1llık restorasyonların retansiyon, marjinal kenar renklemesi, renk uyumu, yüzey yapısı ve sekonder çürük açısından anlamlı düzeyde farklılık gösterdiği görülmüştür. Tanner ve ark. posterior dişlerde fiberle güçlendirilmiş kompozit restorasyonların klinik değerlendirmesini yaptıkları 2,5 yıllık takip sonuçlarında, hasta yaşı ve restore edilen yüzey sayısının, dolgunun anatomik formu ve marjinal renk bozulması üzerinde anlamlı ölçüde öneme sahip olduğunu ve duvar sayısı fazla olan restorasyonların daha düşük kayıp oranına sahip olduğunu belirtmişlerdir (17). Pallesen ve Dijken, resrospektif olarak posterior kompozit restorasyonlar1 30 yıllık değerlendirdikleri çalışmalarında, major problemin oklüzal aşınmadan dolayı restorasyonun anatomik formunun kaybedilmesi olduğu belirtmiştir (18). Materyalin yüzeyindeki aşınmalar, yeterli seviyede cilalanmamış bir yüzey yapısı, yetersiz anatomik form, materyalin su ve diğer boyayıcı maddeleri absorbe etmesi, kompozit rezinde renk uyumsuzluğuna sebebiyet vermektedir. Renk değişimlerinin bir diğer sebebi de, materyalin organik rezin matriks içeriğinin farklı olmasıdır. Örneğin yüksek TEGDMA yüzdesi, kompozitin vizközitesini azaltırken, su emilimini ve diğer boyar maddelerin emilimini arttırmaktadır (19). Ayrıca, polimerize olmadan kalan matriks içerisindeki monomerler, fotoinitiatör ve koinitiatörler de renk uyumsuzluğunda önemli klinik etkiler gösterebilirler (20).

Sekonder çürüklerin, restorasyon yapımını takiben, minimum iki yıl sonra gözlenebildiğini bildiren çalışmalarla beraber (13), bu kriter 6-17 yıllık restorasyonlarda en sik başarısızlık nedeni olarak gösterilmektedir $(21,22)$. Ancak çalışmamızda sekonder çürük başarısızlık oranı ilk sıralarda yer almamaktadır. Bunun nedeni, sond kullanılarak yapılan muayenelerde makro düzeydeki yüzey aşınmalarının ve gözle muayene de rahatlıkla belirlenebilen renk farklılıklarının, mikro düzeydeki marjinlerde sızıntı ve sekonder çürük ile sonuçlanabilen defektlere göre daha kolay görülebilir olması ile açıklanabilir. Sekonder çürükler, çoğu zaman radyografik muayenelerde de röntgenin ve çürügüün pozisyonundan dolayı gözden kaçırılmaktadır. Direk restorasyonlarla indirek restorasyonlar kıyaslandığında, indirek restorasyonlardaki düşük sekonder çürük insidansını, marjinal bütünlüğün 20 yıllık takip periyodunda dahi bozulmadan kalması ile ilişskilendirilmiştir (23). Bizim bulgularımız da, bu bulgularla uyumlu olarak başarısızlık kriterleri birbirine yakın oranlarda çıkmış ve bu kriterlerin birbiri ile ilişkili olup birbirini etkilediği görülmektedir.

Çalışmamızda, amalgam dolgu materyali kullanılarak yapılan restorasyonların başarısızlık oranı \%69 ve kompozit rezin kullanılarak yapılan restorasyonların başarısızlık oranı $\% 50,8$ olarak bulunmuştur ve aralarında istatiksel olarak anlamlı bir fark bulunmaktadır. Oranların bu şekilde yüksek çıkmasının nedeni, herhangi bir kriterden $\mathrm{C}$ notunu alan restorasyonun başarısız kabul edilmesi ve coğrafi olarak çalışmanın yapıldığı bölgenin dezavantajları olarak düşünülebilir. Ancak restorasyonların yalnızca \%12.8'nin ağızda varlığını sürdürmediği ve restorasyonun yenilenmesine gerek duyulduğu belirtilmelidir. Opdam ve ark. yaptıkları iki farklı klinik çalışmada posterior kompozit restorasyonların sağ kalım oranlarının \%65,2 ile \%92,5 arasında değişmekte olup, takip süreleri 3 ile 17 yıl arasında değişmektedir $(24,25)$. 
Alvanforoush yaptı̆̆ incelemesinde, 24 aydan daha kısa bir değerlendirme dönemini ele alan çalışmaları inceleme dışı bırakmış ve uzun süreli posterior kompozit restorasyonların performansı üzerine yayınlanan klinik çalışmaları on yıllık süreçlere bölerek (1995-2005/ 20062016) dahil etmiştir. Her on yılda kompozit rezin restorasyonların, sağ kalım/başarısızlı oranı, değerlendirme süresi ve başarısızlık nedenleri ile ilgili kayıtları analiz etmiştir. 1995-2005' teki çalışmalar için genel sağ kalım/başarısızlık oranları sırasıyla $\% 89,41 / \% 10,59$ ve 2006-2016 için \%86,87/\%13,13 idi. 1995-2005'te, başarısızlık nedenleri; sekonder çürük $(\% 29,47)$, kompozit kırığ $1(\% 28,84)$ ve diş kırığ1 $(\% 3,45)$ olup, 2006-2016 ile karşılaştırıldığında bu yıllarda ki başarısızlık nedenlerinin sekonder çürük $(\% 25,68)$, kompozit kırık $(\% 39,07)$ ve diş kırığı $(\% 23,76)$ olduğu gözlemlemişlerdir. Son on yılda sekonder çürük, postoperatif duyarlılık, yetersiz marjinal adaptasyon ve aşınmanın yanı sıra başarısızlık nedeni olarak kompozit kırığı, diş kırığı ve endodontik tedavi ihtiyacı görülme sıklığında artış kaydedilmiştir. Genel başarısızlık oranları çok az farklılık göstermesine karşın, başarısızlık nedenleri dikkate değer bir değişiklik göstermiştir. Bu değişimin sebebi olarak, daha büyük restorasyonlar için kompozit kullanımının artması ve muhtemelen materyal özelliklerindeki değişikliklerin bir yansıması olduğu sonucuna varmıştır (26).

Moraschini ve ark. ise yaptıkları meta-analiz çalışmasına, yüksek kaliteli randomize kontrollü çalışmaları, kontrollü klinik araştırmaları ve prospektif ve retrospektif kohort çalışmaları dahil etmişler ve posterior dişlerdeki kompozit rezin restorasyonlarının, amalgam restorasyonlara kıyasla daha az uzun ömürlü ve daha fazla sayıda sekonder çürüğe sahip olduğunu göstermişlerdir. Restorasyonlardaki kırıklarla ilgili olarak, iki restoratif materyal arasında en az 12 aylık takip süresi açısından istatistiksel olarak anlamlı bir fark olmadığını da belirtmişlerdir (27).

Bernardo ve ark. amalgam ve kompozit restorasyonları değerlendirdikleri yedi yıl takipli çalışmalarında, kompozit restorasyonların amalgamlara göre ortalama yıllık başarısızlık oranının üç kat fazla olduğunu bulmuşlardır (28). Ancak yıllar içerisinde kompozitteki gelişmelerle, amalgam ve kompozit restorasyonların sağ kalım süresinin yakın olduğunu gösteren çalışmalar da mevcuttur. Jardim ve ark. çok merkezli, randomize kontrollü klinik çalışmalarında, selektif çürük temizlemesi protokolü uyguladıkları derin çürük lezyonlarını amalgam ve kompozit materyalleriyle restore etmişler ve 5 yıl takiplerinin sonucunda, 172 restorasyon değerlendirilmiş (61'i amalgam ve 111'i kompozit rezin), materyal farketmeksizin benzer başarı oranları gösterdiğini bulmuşlardır (29). Genel olarak kenarları sağlam minede biten ve düşük çürük risk grubundaki kişilerde kompozit tercih edilirken; çok derin ve izolasyonun sağlanmasının rubber dam kullanımında dahi zor olacağı kavitelerde amalgam kullanılabileceği söylenmektedir (30).

Bogacki ve ark 300.000 'den fazla hastayı içine alan kohort bir çalışma yapmışlar ve posterior direkt restorasyonların ağızdaki ömrünün \%90'dan fazla olduğunu, ancak hastalar başka bir hekime gittiklerinde hekimin insiyatif kullanarak bu restorasyonları değiştirmeyi tercih ettiği ve bu oranın beş yıl sonunda \%60'lara kadar düştüğü görülmüştür (31).

Çalışmamızın sonuçlarına göre, hastaya ve restorasyona bağlı faktörlerin yapılan restorasyonların klinik performanslarına etkisi incelendiğinde restorasyonun tipi, restorasyon derinliği, yapıldığı merkez, hastanın sigara içme alışkanlığı, parafonksiyonel alışkanlık ve oral hijyen alışkanlık farklılığ 1 , restorasyonun performansını anlamlı düzeyde etkilemiştir. Ömürlü ve ark. inceledikleri 495 amalgam ve 114 kompozit restorasyonunda en iyi sonuçların, üniversite ögrretim elemanları ile amalgam restorasyonlarda alındığını bulmuşlardır. Ayrıca, restorasyonun yapıldığ 1 merkezin, marjin uyumu ve marjin renklenmesinin çürük ile ilişkili olduğunu tespit etmişlerdir (3). Üzerli ve ark yürüttükleri çalışmada, 283 amalgam ve 150 kompozit rezin restorasyonu değerlendirmiş ve 10 yıldan eski, sınıf 2 (MOD) ve ağız diş sağlığı merkezlerinde uygulanmış restorasyonların, posterior direk restorasyonlar için başarısızlıkla ilişkilendirilebilecek kriterler olduğunu bulgulamışlardır (32). Rodolpho ve ark. özel muayenehanede yaptıkları 17 yıllık klinik çalışmada, 282 restorasyon arasında yaklaşık \%34,8 başarısızlık gözlerken, değerlendirilen posterior kompozit rezin restorasyonların klinik performansını 17 y1ldan sonra bile kabul edilebilir düzeyde olduğunu göstermişlerdir. Bununla birlikte, molar dişlerde, Sınıf II kavitelerde ve büyük restorasyonlarda kompozit rezin restorasyonların başarısız olma olasılığının daha yüksek olduğu belirtilmiştir (33). Bizim sonuçlarımızda da restorasyon derinliği arttıkça, başarı oranı da istatistiksel olarak anlamlı farklılık gösterecek kadar düşmektedir ve yine literatürdeki diğer çalışmalarla uyumlu olarak en yüksek başarı oranı üniversite öğretim elemanı tarafından yapıldığında, en yüksek başarısızlık oranı ise ADSM'de yapılan restorasyonlarda olduğu görülmektedir.

Yapılan bir çalışmada, sigara içen insanların dişlerinin mine yüzeyindeki olası değişiklikleri inceleme amaçlanmış ve sigara içen kişilerin diş yüzeyinin mine yapısını ve mekanik özelliklerini olumsuz etkilediği ve hatta normal remineralizasyon sürecini aksattığı görülmüştür (34). Zanetti ve ark. sigara dumanının, diş dokuları ve rezin kompozitler üzerindeki etkisini araştırdıkları çalışmalarında, sigara dumanının kompozitler üzerinde renk değişikliği yaptığını göstermişlerdir (35). Bizim çalışmamızda da sigara içenlerdeki restorasyonların başarı oranı, içmeyenlere göre anlamlı derecede daha düşüktür.

Laske ve ark. restorasyonların sağ kalım sürelerindeki risk faktörlerini inceledikleri çalışmalarında parafonksiyonel alışkanlıkların restorasyon ömrü için yüksek risk faktörü olduğunu göstermişlerdir (36). Çalışmamızın sonuçlarına göre, geceleri diş sıkma alışkanlığı olanların \%44,3, sakız çiğneme alışkanlığı olanların \%16 ve bruksizim olanların \%47,5 başarı oranı tespit edilmiştir.

Yapılan bir çalışmada in vitro ve in vivo olarak kompozit materyallerinin biyofilme maruz birakıldığı ve lipaz çözeltisine daldırıldığında yüzey özellikleri incelenmiş ve özellikle firçalama yapılmadığında yüzey bozulmalarında artış görülmüştür (37). Çalışmamızda da her gün 1-2 kez diş firçalayanlarda başarı oranı $\% 49,7$ iken haftada 1-2 kez dişlerini firçalayanlarda başarı \%22,2'ye düşmekte ve 
ayda 1-2 kez ila dişlerini hiç firçalamayan hasta grubunda başarı görülememiştir.

Bölgedeki hastanemize başvuran hastaların sosyoekonomik ve eğitim durumları göz önüne alındığında ağı hijyeni, karyojenik beslenme alışkanlıkları, düşük estetik beklenti gibi nedenlerle hekimlerde gerekli özeni göstermemekte ve restorasyonlarda daha yüksek başarısızlık oranları görülmektedir. Hekimlerin, bölgedeki nüfus yoğunluğu da dikkate alındığında, fazla sayıda hastanın tedavisini mümkün olabilen en kısa sürede gerçekleştirme gayesi içinde olması, bazı tedavi gereksinimlerini özellikle de teknik hassasiyet isteyen adeziv restorasyonlarda atlayabilmektedirler. Bölgede yetkin olmayan kişilerin açtığı, yetersiz dental ekipmanların ve sosyoekonomik seviyesi daha düşük olan hasta grubuna hitap eden özel kliniklerin sayısının azımsanamayacak olması gerçeği de göz önüne alındığında teknik hassasiyet isteyen direk posterior restorasyonlarda başarısızlık oranları yüksek görülmektedir.

\section{SONUÇ}

Direk posterior restorasyonların ağız içi sağ kalım süresi, uygulayan diş hekimi tecrübesi ve bilgi birikimi, uygulama aşamalarındaki titizlik, restoratif materyali tanıma ve vakaya uygun seçim kriterleri bilgisi ve hastaya bağlı çeşitli faktörlerden etkilenmekte ve restorasyonların başarısının doğrudan bu etkenlere bağlı olduğu görülmektedir. Hastaya ve ülke ekonomisine ek maliyetler getirmemesi ve hem diş hekimlerinin hem hastaların zaman ve emek kaybı yaşamaması için, ilgili risk faktörlerinin dikkatle belirlenip, etkili tedavi planlamaları bu doğrultuda yapılmalıdır. Ancak bu şekilde başarısızlıkların önüne geçilebilir ve restorasyonun idamesi uzun süreli sağlanabilir.

Yazarların katkıları: Fikir/Kavram: E.P.B.; Tasarım: E.P.B., E.S., S.A.Y.; Veri Toplama ve/veya İşleme: E.S., S.A.Y.; Analiz ve/veya Yorum: E.S.; Literatür Taraması: E.S., S.A.Y; Makale Yazımı: E.S.; Eleştirel İnceleme: E.P.B., Ş.B.

\section{KAYNAKLAR}

1. Marcenes W, Kassebaum NJ, Bernabe E, Flaxman A, Naghavi M, Lopez A. Global burden of oral conditions in 1990-2010: a systematic analysis. Journal of Dental Research. 2013; 92(7): 592-7.

2. Affairs, ACOS. Direct and indirect restorative materials. The Journal of the American Dental Association, 2003; 134(4): 463-72.

3. Ömürlü H, Arısu HD, Eligüzeloğlu E, Üçtaşlı MB, Bala O. Gazi üniversitesi diş hekimliği fakültesi diş hastalıkları ve tedavisi anabilim dalına başvuran hastaların direkt restorasyonlarının klinik başarısının değerlendirilmesi. GÜ Diş Hek Fak Derg. 2011; 28(1): 23-8.

4. Manhart J, Garcia-Godoy F, Hickel R. Direct posterior restorations: clinical results and new developments. Dent Clin North Am. 2002; 46(2): 303-39.

5. Hickel R, Manhart J. Longevity of restorations in posterior teeth and reasons for failure. J Adhes Dent. 2001; 3(1): 45-64.
6. da Silva Pereira RA, da Silva GR, Barcelos LM, Cavalcanti KGBA, Herval AM, Ardenghi TM, Soares CJ. Practice-based analysis of direct posterior dental restorations performed in a public health service: Retrospective long-term survival in Brazil. PLoS One. 2020; 15(12): e0243288.

7. Flavio Fernando Demarco FF, Collares K, Correa MB, Cenci MS, de Moraes RR, Opdam NJ. Should my composite restorations last forever? Why are they failing?. Braz. Oral Res. 2017; 31: e56.

8. Kopperud SE, Tveit AB, Gaarden T, Sandvik L, Espelid I. Longevity of posterior dental restorations and reasons for failure. Eur J Oral Sci. 2012; 120(6): 539-48.

9. Kubo S, Kawasakı A, Hayashi Y. Factors associated with the longevity of resin composite restorations. Dent Mater J. 2011; 30(3): 374-83.

10. Lucarotti PS, Holder RL, Burke FJ. Outcome of direct restorations placed within the general dental services in England and Wales (Part 3): variation by dentist factors. J Dent. 2005; 33(10): 827-35.

11. Demarco FF, Correa MB, Cenci MS, Moraes RR, Opdam NJM. Longevity of posterior composite restorations: not only a matter of materials. Dent Mater. 2012; 28(1): 87-101.

12. Demarco FF, Collares K, Coelho-de-Souza FH, Correa MB, Cenci MS, Moraes RR et al. Anterior composite restorations: a systematic review on longterm survival and reasons for failure. Dent Mater. 2015; 31(10): 1214-24.

13. Heintze SD, Rousson V. Clinical effectiveness of direct class II restorations: A meta-analysis. J Adhes Dent. 2012; 14(5): 407-31.

14. Manhart J, Chen H, Hamm G, Hickel R. Buonocore Memorial Lecture. Review of the clinical survival of direct and indirect restorations in posterior teeth of the permanent dentition. Oper Dent. 2004; 29(5): 481508.

15. Üçtaşlı MB, Can HE, Omurlu H. Amalgam restorasyonların değiştirilme nedenleri ve klinik ömrü. A. Ü. Diş Hek. Fak. Derg. 2002; 29(1): 9-16.

16. Van Dijken JW, Pallesen U. A six-year prospective randomized study of a randomized study of a nanohybrid and a conventional hybrid resin composite in class II restorations. Dent Mater. 2013; 29(2): 191-8.

17. Tanner J, Tolvanen M, Garoushi S, Säilynoja E. Clinical evaluation of fiber-reinforced composite restorations in posterior teeth - results of 2.5 year follow-up. Open Dent J. 2018; 12: 476-85.

18. Pallesen U, JWV van Dijken. A randomized controlled 27 years follow up of three resin composites in class II restorations. J Dent. 2015; 43(12): 1547-58.

19. Freitas F, Pinheiro de Melo T, Delgado AH, Monteiro P, Rua J, Proença L, et al. Varying the polishing protocol influences the color stability and surface roughness of bulk-fill resin-based composites. Journal of Functional Biomaterials. 2021; 12(1): 1.

20. Ünlü N, Ülkü S. Son 10 yılda kompozit rezin restorasyonlar: In vivo ve in vitro çalışmalarla bir derleme. Necmettin Erbakan Üniversitesi Diş Hekimliği Dergisi. 2020; 2(3): 124-45. 
21. Astvaldsdottir A, Dagerhamn J, Van Dijken JW, Naimi-Akbar A, Sandborgh-Englund G, Tranæus S, Nilsson M. Longevity of posterior resin composite restorations in adults-A systematic review. J Dent. 2015; 43(8): 934-54.

22. Beck F, Lettner S, Graf A. Survival of direct resin restorations in posterior teeth within a 19-year period (1996-2015): A meta-analysis of prospective studies. Dent Mater. 2015; 31(8): 958-85.

23. Ravasini F, Bellussi D, Pedrazzoni M, Ravasini T, Orlandini P, Meleti M, Bonanini M. Treatment outcome of posterior composite indirect restorations: a retrospective 20- year analysis of 525 cases with a mean follow-up of 87 months. Int $\mathrm{J}$ Periodontics Restorative Dent. 2018; 38(5): 655-63.

24. Opdam NJM, Bronkhorst EM, Roeters JM, Loomans BAC. Longevity and reasons for failure of sandwich and total-etch posterior compositeresin restorations. J Adhes Dent. 2007; 9(5): 469-75.

25. Opdam NJ, Loomans BA, Roeters FJ, Bronkhorst EM. Five-year clinical performance of posterior resin composite restorations placed bydental students. J Dent. 2004; 32(5): 379-83.

26. Alvanforoush N. Palamara J, Wong RH, Burrow MF. Comparison between published clinical success of direct resin composite restorations in vital posterior teeth in 1995-2005 and 2006-2016 periods. Australian Dental Journal. 2017; 62(2): 132-45.

27. Moraschini V, Fai CK, Alto RM, Dos Santos GO. Amalgam and resin composite longevity of posterior restorations: A systematic review and meta-analysis. J Dent. 2015; 43(9): 1043-50.

28. Bernardo M, Luis H, Martin MD, Leroux BG, Rue T, Leitao J, et al. Survival and reasons for failure of amalgam versus composite posterior restorations placed in a randomized clinical trial. J Am Dent Assoc. 2007; 138(6): 775-83.

29. Juliana JJ, Heliana DM, Barbara K, Lilian M, Luana SA, Paulo MY, et al. Restorations after selective caries removal: 5-year randomized trial. Journal of Dentistry. 2020; 99: 103416.

30. Soares AC, Cavalheiro A. A review of amalgam and composite longevity of posterior restorations. Reu Port Estomatol Med Dent Cir Maxilofac. 2010; 51(3): 155-64.

31. Bogacki RE, Hunt RJ, del Aguila M, Smith WR. Survival analysis of posteriro restorations using an insurance claims database. Oper Dent. 2002; 27(5): 488-92.

32. Uzer Çelik E, Yazkan B, Tunaç AT. Assessment of the factors affecting the clinical performance of direct posterior restorations. EÜ Dişhek Fak Derg. 2016; 37(2): 99-106.

33. Da RR, Paulo A. A clinical evaluation of posterior composite restorations: 17-year findings. Journal of Dentistry. 2006; 34(7): 427-35.

34. Ibrahim HF, Hassan GS. Qualitative and quantitative assessment of the potential effect of cigarette smoking on enamel of human smokers' teeth. Archives of Oral Biology, 2021; 121: 104953.

35. Zanetti F, Zhao X, Pan J, Peitsch MC, Hoeng J, Ren Y. Effects of cigarette smoke and tobacco heating aerosol on color stability of dental enamel, dentin, and composite resin restorations. Quintessence Int. 2019; 50(2): 156-66.

36. Laske M, Opdam NJM, Bronkhorst EM, Braspenning JCC, Huysmans MCDNJM. Risk factors for dental restoration survival: A practice-based study. J Dent Res. 2019; 98(4): 414-22.

37. Kusuma Yulianto HD, Rinastiti M, Cune MS, de Haan-Visser W, Atema-Smit J, Busscher HJ, et al. Biofilm composition and composite degradation during intra-oral wear. Dent Mater. 2019; 35(5): 74050 . 